UDC: $821.134 .2(862) .09$ Vallejo F.

$821.134 .2(862)$ ' $255.54=163.6$

DOI: https://doi.org/10.18485/hispserb.2019.2.ch21

\author{
Jasmina Markič ${ }^{\mathbf{1}}$ \\ Universidad de Ljubljana \\ Eslovenia
}

\title{
TRADUCIENDO A FERNANDO VALLEJO: LA RAMBLA PARALELA Y VZPOREDNA ULICA
}

\section{Resumen}

La Rambla paralela de Fernando Vallejo (Medellín, Colombia, 1942), publicada en 2002, es una novela de autoficción con un específico tratamiento de las voces narrativas que oscilan de modo permanente entre la primera y la tercera persona y con temas recurrentes como el paso del tiempo y la muerte. Un anciano escritor colombiano es invitado a hablar en la feria de libros de Barcelona en la que el país invitado es Colombia. El escritor deambula por Barcelona y bajo la influencia del alcohol y el insomnio se sumerge en sus recuerdos del pasado. Los tiempos del presente, pasado y futuro se funden así como los espacios paralelos por los que se mueve el protagonista (Barcelona, Medellín, México...) que al final morirá en la capital catalana.

El presente artículo analiza algunos aspectos de la traducción, mayoritariamente léxicos pero también morfosintácticos, de la novela La Rambla paralela y su versión eslovena Vzporedna ulica (2018) traducida por Ferdinand Miklavc, sin dejar de lado el marco socio-cultural e histórico que se refleja en la novela. Abundan los diálogos y el habla de la esfera coloquial y local. El trabajo examina y comenta la traducción comparada con el original, sobre todo con referencia a los colombianismos y los términos y locuciones específicos de la región que presentan uno de los mayores obstáculos para el traductor.

Palabras clave: Fernando Vallejo, traducción, colombianismos, la variante antioqueña, paralelismos.

\footnotetext{
${ }^{1}$ jasmina.markic@ff.uni-lj.si
} 


\section{Introducción}

En este estudio se presentan diferentes posibilidades y dificultades a las que se enfrenta el traductor de una obra escrita en un estilo vallejiano brillante y muy particular en cuanto al uso de giros y términos típicos de Colombia y/o de Antioquia. Se trata de colombianismos en general y de expresiones típicas de la zona de Medellín, Antioquia, en particular, a lo que el mismo autor / narrador llama la atención²:

El viejo escribía en español pero se hablaba en antioqueño. A mí con lo experto que soy en leer pensamientos, les confieso que a veces me costaba entenderlo. (LRP 54)

El análisis contrastivo se basa en los estudios realizados por Montes Giraldo (1982, 1985) y Flórez (1963) sobre el español de Colombia y la dialectología colombiana con el respaldo de los diccionarios de colombianismos (1983 y 2018), el Diccionario de la Lengua Española de la RAE y el diccionario de la lengua eslovena estándar SSKJ citados más abajo.

\section{Sobre la Rambla paralela}

La Rambla paralela tiene un título significativo: indica el paralelismo del tiempo y del espacio. El narrador se mueve en diferentes tiempos. El presente es su estancia en Barcelona a donde fue invitado a participar en la Feria del Libro como escritor; el pasado son sus recuerdos de la infancia en Medellín, su juventud, sus viajes; el futuro es su muerte ya que deambula por Barcelona como un fantasma. Los espacios paralelos son Barcelona, en la que se encuentra como un viejo escritor colombiano a punto de morir y en la que estuvo de joven, y el Medellín de su infancia. Además irrumpen otros lugares en sus recuerdos: México, Nueva York, Roma... El protagonista es Fernando, su álter ego, que narra en la primera persona de singular y se desdobla en un narrador de tercera persona, "una voz narrativa que no se presenta única ni de forma clara sino en constante desplazamiento y cambio de perspectivas." (Musitano 2012). Según esta autora la literatura de Fernando Vallejo, "escritor colombiano devenido mexicano", se inscribe en la autobiografía y más concretamente en la

\footnotetext{
${ }^{2}$ Al final de cada ejemplo presentado figuran los datos sobre el título y la página: (LRP más el número de la página) para La Rambla paralela y (VU más el número de la página) para la novela traducida al esloveno Vzporedna ulica.
} 
autoficción. Es una literatura del recuerdo: el narrador de sus novelas, "que es él y no es él, es un ser de recuerdo que no conoce de tiempos ni de espacios definidos, y que, a pesar de envolverse en ese tono cínico, irónico y antipatriótico, detrás aparece un melancólico rodeado de afectos y de muertes que no lo dejan seguir viviendo." (Musitano 2012). La novela es también una feroz crítica de la situación en Colombia y tiene múltiples referencias a situaciones históricas y actuales, referencias geográficas, culturales y lingüísticas (p. ej. críticas del mal uso del español etc.).

\section{El español de Colombia y los colombianismos}

Una de las acepciones de colombianismo que ofrece la $23^{a}$ edición (2014, versión electrónica) del Diccionario de la lengua española de la RAE (a continuación DLE) es "1. m. Palabra o uso propios del español hablado en Colombia".

El Nuevo diccionario de colombianismos (a continuación NDC) dirigido por Haensch y Werner (1993) utiliza como criterio principal de selección de entradas en el diccionario la diferencia de uso entre el español colombiano y el peninsular (1993: XIV).

En el Diccionario de colombianismos (2018) del Instituto Caro y Cuervo de Bogotá (a continuación DC), en el apartado de Características generales del diccionario, se afirma que "el concepto de colombianismo que se maneja en el Diccionario es diferencial, es decir, el término, expresión o sentido considerado colombianismo se usa en cualquier región de Colombia, pero no en el español peninsular" (2018: 17).

Tanto el NDC de 1993 como el DC de 2018 ofrecen marcas regionales en sus entradas ya que uno de sus objetivos principales es incluir términos de todas las regiones lingüísticas de Colombia.

"El español de Colombia es una variedad de la lengua española compuesta por un conjunto de hablas regionales con rasgos específicos de pronunciación, de entonación y de vocabulario, principalmente, que permiten su clara diferenciación frente a otras modalidades nacionales" (Bernarda Espejo). Desde el punto de vista de la dialectología, el español de Colombia ha sido una de las variantes del español de América más estudiadas $^{3}$. En 1982 Montes Giraldo (apud Alvar 1996: 136-142),

\footnotetext{
${ }^{3}$ Una obra muy importante sobre el español de Colombia es el Atlas Lingüístico y Etnográfico de Colombia (ALEC) dirigido por Luis Flórez y publicada por el Instituto Caro y Cuervo entre 1981 y 1983; también existen numerosos estudios sobre diferentes dialectos de renombrados investigadores como Luis Flórez (1963), Germán de Granda (1978), Montes Giraldo (1985), Manuel Alvar (1996) y muchos otros.
} 
basándose en los datos del ALEC, propuso clasificar los dialectos de Colombia en dos grandes superdialectos: el superdialecto costeño (que comprende el costeño caribe y el costeño pacífico) y el superdialecto central o andino (que comprende el centro-oriental y el centro-occidental). De acuerdo con esta clasificación, el departamento de Antioquia de Colombia y su capital Medellín hacen parte del superdialecto central o andino del centro-occidental (paisa o antioqueño).

La obra de Fernando Vallejo abunda en colombianismos de uso general en Colombia como también de voces típicas antioqueñas. En ambos casos la traducción al esloveno exige bastante esfuerzo, investigación y búsqueda de soluciones aceptables en el texto meta. En muchos casos el traductor resolvió de manera creativa estas situaciones.

\section{Características lingüísticas y culturales}

Los eventos pasados y presentes se funden a menudo en el texto. El recuerdo de los acontecimientos históricos y la crítica punzante de los hechos actuales están presentes a lo largo de la novela. El ejemplo siguiente se refiere a un evento histórico importante, el bogotazo, que además se explica en el mismo texto y se mantiene como tal en la traducción eslovena.

El bogotazo fue la revuelta popular que destruyó el centro de Bogotá a mediados del siglo y que prendió la mecha del incendio. (LRP 26)

Bogotazo je bila ljudska vstaja sredi stoletja, v kateri je bilo uničeno središče Bogote in ki je prižgala vžigalno vrvico požara. (VU 19)

La traducción de términos típicos, culturemas, frasemas, expresiones referentes a las tradiciones de la región siempre presentan bastantes dificultades para el traductor. En el ejemplo LRP 43 el narrador se refiere al verraco'e Guaca. Se trata de una leyenda antioqueña de un cerdo semental, un verraco, que se escapaba del corral para buscar a las marranas, andaba por las salinas y los sembrados de Heliconia, matando gallinas, atacando a otros animales, y sembrando pánico entre la gente. Los paisas ${ }^{4}$ comenzaron a darles el apodo de verraco a los campesinos mujeriegos y pendencieros. A Heliconia, un municipio de Antioquia, solían decirle Guaca por el gran número de guacas (entierros indígenas) ricas en objetos de oro.

\footnotetext{
${ }^{4}$ Paisa se refiere a los habitantes de las regiones colombianas de Antioquia, Caldas, Risaralda, Quindío, noroccidente del Tolima y norte del Valle del Cauca.
} 
El DC presenta cinco acepciones de verraco, ca / berraco, ca: adj. 1 inf. Referido a una persona, que está furiosa, de mal genio; 2 inf. Referido a una situación o tarea, que es difícil de sobrellevar o resolver; 3 vulg. Referido a una persona, que está excitada sexualmente; adj. /s. 4 inf. Referido a una persona, que se destaca por una cualidad o que realiza bien algún trabajo; 5 inf. Referido a una persona, valiente.

La traducción eslovena no refleja ese sentido de valiente, de "macho", ni se manifiesta la relación con el Verraco de Guaca ('e Guaca) que tiene un monumento en Heliconia y hasta un poema dedicado a él.

- A Colombia lo que le falta es una ley que prohíba la proliferación de leyes -diagnosticó el viejo-. Y otra que prohíba la proliferación de gente. Y una vieja verraca como el verraco 'e Guaca que las haga cumplir.

¿Sabe usted quién es o fue el verraco'e Guaca? ¡Qué va a saber! Ya no queda ni uno en este mundo que lo sepa. Los que sabían se murieron y la expresión desapareció. (LRP 43)

»V Kolumbiji manjka zakon, ki bi prepovedoval množenje zakonov«, je ugotovil starec. »In še eden, ki bi prepovedoval razmnoževanje ljudi. In en stari frajer, kot frajer e'Guaca, ki ju bo izvrševal.

Veste, kdo je, oziroma je bil frajer e 'Guaca? Kaj boste vedeli! Na svetu ni niti enega več, ki bi vedel. Tisti, ki so vedeli, so umrli, in izraz je izginil. (VU 33-34)

Misia seguido de un nombre es forma de tratamiento y se usa todavía entre muchos campesinos, y en Antioquia también, inclusive, entre personas cultas: misia María. (Flórez 1963: 277) tanto para expresar cariño como respeto. El traductor utiliza un término arcaico esloveno milostljiva como forma de tratamiento que hoy día es obsoleto y se usaba en el entorno burgués como forma de tratamiento cortés.

¿Pero estoy hablando a la finca Santa Anita, la que está entre Envigado y Sabaneta, saliendo de Medellín, Colombia?

- A la misma. Al aire que quedó.

- Y que es de Raquel Pizano.

- Era: de misiá Raquelita. ¡Cuánto hace que murió! (LRP 10)

»Toda, saj govorim s posestvom Santa Anita, s tem, ki je med Envigadom in Sabaneto, iz smeri Medellína, Kolumbija?»

»Prav s tem. Z zrakom, ki je ostal.»

»In kaj je z Raquel Pizano.»

»Bilo: z milostljivo Raquelito. Kdaj je že umrla!« (VU 5) 
Una de las características del habla antioqueña en cuanto a las formas de tratamiento es el voseo, forma de tratamiento familiar que alterna con el tuteo. Flórez constata ya en 1963 la presencia de ambas formas, vos y tú:

Tú es de empleo corriente en Bogotá y en la costa atlántica. Hoy parece que gana terreno en las ciudades. Vos se emplea como singular, y es tratamiento de mucha confianza en algunas regiones (sobre todo Antioquia, Caldas, Valle, zona andina de Nariño - hacia el Ecuador - etc.); se usa con formas verbales en -ás, -és, -ís, y confundido muchas veces con tú (ipor qué no hablas?, ¿qué tenes?, ¿vos qué decís?, sentaté). Aunque el tuteo y el voseo parece que se van extendiendo en Colombia, todavía el tratamiento de uso más general y corriente es usted (entre iguales, de superior a inferior y de inferior a superior). (Flórez 1963: 276)

Según Montes Giraldo (1967: 33) la zona etnolingüística antioqueña va más allá de los límites del departamento de Antioquia. Afirma el autor que "en ninguna otra zona parece alcanzar el voseo tal generalidad e intensidad de uso en todas las clases sociales". Una de las posibles razones para la extensión del voseo como tratamiento general de confianza a todas las clases sociales en esta región noroccidental de Colombia (Antioquia y Caldas) era el tipo de sociedad abierta y bastante igualitaria que se formó en la época de la colonización (Montes Giraldo 1967: 38), lo que se reflejaba también en las formas de tratamiento. En el texto analizado hay muchos ejemplos de voseo y tuteo, sin una clara diferencia de uso de tú o de vos. En esloveno se traduce con la segunda persona de singular como forma de tuteo (tikanje). En la traducción eslovena del ejemplo (VU 51) se pierde el juego de palabras pero el sentido del voseo como marca típica del antioqueño se transmite con una solución feliz del traductor: el "tuteo a la antioqueña".

- ¡Qué bueno que te moriste, abuela, muy a tiempo! Te escapaste de Gaviria y de Samper.

Y se ponía a maldecir de los dos bellacos.

- ¡A quién carajos le importan ese par de hijueputas en Barcelona! -le hacía ver yo-. Meditá, razoná, sopesá las cosas...

Le hablaba de «vos» como antioqueño por seguirle la corriente. [...] (LRP 63)

»Kako dobro, da si umrla, stara mama, ravno o pravem času! Izognila si se Gaviriu in Samperju. 
In je začel preklinjati oba lopova.

Kdo za vraga se v Barceloni meni za ta par kurbinsinov«, sem ga opozoril. »Premišljuj, razmišljaj, tehtaj reči...»

Tikal sem ga po antioquijsko, da bi ostajal v toku z njim. [...] (VU 51)

- Los oía, los sentía, los olía, pero no los veía. ¡Claro, cómo los iba a ver si iba con los ojos cerrados!

- ¡Abrilos, güevón, que te van a atropellar! (LRP 128)

Slišal jih je, čutil jih je, vohal jih je, vendar ni videl. Jasno, kako naj jih vidi, če je hodil z zaprtimi očmi!

»Odpri jih, tepec, saj te bodo povozili!« (VU 106)

Fernando Vallejo introduce en su escrito muchas unidades fraseológicas ${ }^{5}$ (locuciones, paremias, sobre todo refranes y proverbios) también comparaciones estereotipadas, metáforas. El traductor logra, en muchos casos, traducir el refrán o proverbio original con otro esloveno que le es equivalente en el significado y a veces en el significad o y la forma. Los proverbios y refranes son tanto de uso general en español como también de uso limitado a la zona hispanoamericana o/y colombiana.

- ¡Qué hijueputas tan lambiscones! Lamiéndoles el culo a los muertos como si siguieran vivos. "Vaca vieja no olvida el portillo" decía la abuela. (LRP 112-113)

»Kakšni prekleti laskači! Mrtvim ližejo rit, kot da bi bili še živi.« »Stara navada, železna srajca,» je rekla stara mama. (VU 93-94)

El que se va a Sevilla pierde su silla. (LRP 122)

Priložnost izgubljena, ne vrne se nobena. (VU 101)

Nadie habla, todos callan. Allá solo habla el presidente, que habla y habla sin parar. Habla hasta por los codos como una cotorra mojada a la que le hubieran soltado la lengua con vino de consagrar. (LRP 136)

Nihče ne spregovori, vsi molčijo. Tam govori samo predsednik, ki govori in govori brez nehanja. Govori kot dež, kakor mokra papiga, ki so ji razvezali jezik z mašnim vinom. (VU 113)

$\overline{{ }^{5} c / f \text { Corpas Pastor }}$ de 1996. 
[...] Ah, pero eso sí, las que sí no habían cambiado eran las faltas, los atropellos al idioma que Cuervo censuró y que ahí seguían tan campantes como un gallo montado en su gallina. (LRP 41)

Ah, toda seveda, spremenile pa se niso napake, pačenje jezika, ki jih je Cuervo obsojal in so se tu košatile kakor petelin na svoji kuri. (VU 32)

¡Y para adelante, viejo, que vamos arriando mulas! (LRP 80)

In naprej, starec, saj priganjamo mule! (VU 65)

En la novela destacan los diminutivos típicos del uso colombiano que señalan frecuentemente un tono irónico, a veces sarcástico del estilo vallejiano. Sin embargo, también pueden indicar una postura positiva con un valor pragmático. En el ejemplo LRP 124 el diminutivo viajecito se traduce al esloveno (potovanjce) y en ambos casos tiene la función de disminuir la importancia de la ausencia del narrador para consolar a la abuela. Pero el uso del vos en este ejemplo, que en la novela aparece alternando con el tuteo, no se distingue en esloveno y se traduce como tuteo esloveno en $2^{\text {a }}$ persona de singular.

- ¿Por qué llorás, abuela si no me voy a morir? Si es un simple viajecito de cuatro horas en avión... Tan pronto como pueda vuelvo. (LRP 124)

»Zakaj jokaš, stara mama, saj ne bom umrl? Saj je le običajno štiriurno potovanjce z letalom... Takoj, ko bo mogoče, se vrnem.« (VU 103)

El tono irónico y burlón del texto original (LRP 73) se pierde en la traducción ya que no se traduce con diminutivo ni se expresa de otro modo la ironía.

Cuando remedó a algunos en español el viejo descubrió, por un desliz en el tonito, que era argentino. (LRP 73)

Ko je oponašal neke ljudi v španščini, je starec po nekem spodrsljaju pri poudarku odkril, da je Argentinec. (VU 59)

En LRP 71 se trata de una fuerte crítica de los presidentes de Colombia, que en esloveno están en diminutivo pero sin ninguna explicación al pie de página de quiénes se trata y el porqué de este ataque tan feroz contra ellos. El diminutivo refleja el rencor y el odio por los políticos de Colombia que según Fernando Vallejo echaron a perder el país y lo llevaron a la decadencia y a la violencia. 
La mariquita de Gaviria borró de un plumazo la palabra «honorabilidad» del diccionario de Colombia. Le siguieron al bellaco Sampedrito y Pastranitas, otros dos. (LRP 71) ${ }^{6}$

Pedrček Gaviria jez eno potezo izbrisal besedo »poštenost «iz kolumbijskega slovarja. Lopovu sta sledila Samperitko in Pastranitka (VU 57)

La traducción en VU 61 sí refleja el sarcasmo y la rabia del protagonista. Además el traductor creó un neologismo en esloveno para el término hideputica (diminutivo de hijueputa, variante de hideputa, el DC menciona la palabra hijueputa con marca vulg. Persona despreciable, que actúa con maldad).

La rabia del hideputica agarraba vuelo y el pataleo alentaba su iracundia. (LRP 75)

Togota kurbinsinčka je dobivala zalet in s cepetanjem je spodbuja svoj bes. (VU 61)

En el ejemplo siguiente no se traduce el diminutivo (madurita) al esloveno, sino que se añade un adverbio (čisto - totalmente) con lo que se pierde el tono irónico del original.

Con las continuas masacres y el consiguiente cambio en la composición del electorado, Colombia ya estaba madurita. (LRP 90)

$\mathrm{Ob}$ nenehnih pokolih in torej nenehnih spremembah volilnih seznamov je bila Kolumbija že čisto zrela. (VU 74)

En LRP 125 los diminutivos se traducen al esloveno con excepción del adjetivo okrogle (en español 'redonditas') aunque el uso del diminutivo en esloveno no es tan frecuente como en español de Colombia. Corresponde al estiilo irónico del narrador/autor.

- ¿Y Sartre cómo era?

- Bajito, flaquito, feíto, de gafitas redonditas de carey.

¡Pues cuánta guerra nos dio el maldito!(LRP 125)

\footnotetext{
${ }^{6}$ César Augusto Gaviria fue presidente de Colombia entre 1990 y 1994. Ernesto Samper Pizano fue presidente de Colombia entre 1994 y 1998. Andrés Pastrana fue presidente de Colombia entre 1998 y 2002.
} 
»In kakšen je bil Sartre?«

»Majčken, suhcan, grdkan z okroglimi očalci iz želvovine.«

»Toda koliko se prekleti ni prepiral!«(VU 103)

La Rambla paralela presenta muchos diálogos y monólogos y, por tanto, aparecen términos del registro coloquial. En el léxico hay numerosos colombianismos como lo muestran, a continuación, los ejemplos del original con sus respectivas traducciones al esloveno.

La traducción de güevón al esloveno es de tepec y güevonada bedarija (LRP 54) que suelen tener un sentido menos fuerte, menos peyorativo en esloveno que el término español. El DLE indica como uno de los significados para huevón de donde deriva la forma usada en Colombia güevón: adj. despect. vulg. imbécil (tonto o falto de inteligencia). En el DC se explica huevón, na / güevón, na: s. /adj. vulg. 1. persona que actúa con poca inteligencia o poco entendimiento. 2. juv. afect. Modo de dirigirse a un amigo o a una amiga.

Ente, en el ejemplo LRP 99, es entidad y no cosa, como fue traducido al esloveno (VU 81).

- La Iglesia, güevón, no es una colectividad religiosa sino un ente económico-político, con bancos, barcos, aviones y todo tipo de intereses terrenales. (LRP 99)

»Cerkev, tepec, ni verska skupnost, marveč neka ekonomsko-politična »reč« z bankami, ladjami, letali in z vse sorte posvetnimi interesi.« (VU 81)

El viejo escribía en español pero se hablaba en antioqueño. A mí con lo experto que soy en leer pensamientos, les confieso que a veces me costaba entenderlo.

- Pensá en cristiano, güevón -le decía remedándolo. (LRP 54)

Starec je pisal v španščini, govoril pa si je po antioquijsko. Meni, pa naj bom še tak strokovnjak za prebiranje misli, priznam vam, je bilo včasih zelo težko razumeti ga.

»Misli po krščansko, tepec«, sem mu rekel karajoče. (VU 43)

Se está pudriendo en vida el español, no se va a podrir el latín que está muerto! Dejémonos de güevonadas. (LRP 54)

„Španščina se razkraja zaživa, pa se ne bo razkrojila latinščina, ki je mrtva. Nehajmo z bedarijami.« (VU 43) 
Andén en el español de Colombia se refiere a acera de una calle destinada a los peatones (DC) y no al andén de las estaciones de ferrocarriles como es el uso en el español peninsular. La palabra está traducida correctamente (pločnik) en el ejemplo siguiente.

Se había instalado como un turista más en el Café de la Ópera, que tenía mesas afuera, en el andén del centro. (LRP 12)

Kot običajni turist se je usidral v kavarni opera, ki je imela mize zunaj, na pločniku v centru. (VU 7)

El tinto en Colombia es café puro, negro (DC: tinto m. bebida caliente de café puro sin leche) y no vino, como en España. Provocar significa tener deseos de algo, apetecer (DC). Y el diminutivo tintico señala amabilidad, cortesía o, en casos, ironía. El traductor optó por traducir tinto como negro (črna):

- ¿Le provoca un tintico, maestro?-oyó que la muchacha le ofrecía a uno de los presentes. (LRP 40)

»Mojster bi vam dišala črna?« je slišal dekle, ki se je obrnilo k nekomu od prisotnih. (VU 31)

La que sí se había jodido por completo era la palabra "poeta", que quedó valiendo en su opinión como "hijueputa", pues había tantos de los unos como de los otros: no menos de cinco millones. Así pues, decirle a alguien en Colombia “¿Le provoca un tintico, poeta?” era según él como decirle “¿Le provoca un tintico, hijueputa?". Ah, y eso de "Le provoca un tintico" se traduce así en cristiano: “¿Se le antoja un café?” (LRP 41)

To, kar pa se je res zajebalo do konca, je beseda »pesnik«, ki je po njegovem mnenju postala vredna toliko kot »kurbinsin", saj je enih toliko kot drugih: nič manj kot pet milijonov. Tako da je danes v Kolumbiji nekomu reči: »Bi vam dišala črna, pesnik? « enako, kot če bi rekli: »Bi vam dišala črna, kurbinsin?« Ah, in to »Bi vam dišala črna«, se v krščansko govorico prevede $\mathrm{z:}$ »Bi vam prijala kavica?« (VU 31-32)

El término cocuyo se define en el DLE como: 1. m. Insecto coleóptero de la América tropical, de unos tres centímetros de longitud, oblongo, pardo y con dos manchas amarillentas a los lados del tórax, por 
las cuales despide de noche una luz azulada bastante viva ${ }^{7}$. Está traducido al esloveno como luciérnaga.

Y del Medellín de sus abuelos infestado de pulgas, chinches, piojos y sin inodoros, o a lo sumo un inodoro a la intemperie, de cajón, alumbrado de noche el penitente por los cocuyos titilantes o los rayos burlones de la luna. (LRP 79)

In iz Medellína njegovih starih staršev, okuženega z bolhami, stenicami, ušmi in brez straniščnih školjk, največ eno stranišče pod milim nebom, $\mathrm{v}$ lopi, ponoči spokornik, osvetljen z migljajočimi kresnicami ali porogljivimi luninimi žarki. (VU 65)

En Colombia, como en gran parte de los países hispanoamericanos, se usa el término carro $^{8}$ para automóvil, mientras que en España es coche. El narrador/autor a lo largo de la novela hace referencias a estas diferencias en el uso del idioma en Colombia y en España provocando juegos de palabras de difícil traducción sin una explicación al pie de página. Coche en el español de Colombia significa carreta o lo que es carro en España. Es comprensible la dificultad de la traducción al esloveno. Coche se tradujo como "voz", carreta. Sin embargo, el narrador/autor utiliza dos términos para automóvil, uno típico de España (coche) y el otro típico de Colombia e Hispanoamérica (carro) y no carreta como fue traducido al esloveno.

Un “coche" o carro le pasó zumbando. (LRP 80)

Mimo njega je pripeljal brneč »voz« ali avto. (VU 65)

Para traducir los diferentes términos para 'resaca', dependiendo del país en el que se usan, el traductor esloveno optó por usar diferentes sinónimos eslovenos con el significado de "resaca". El DC presenta la siguiente definición para enguayabado, da, adj.: 1. Referido a una persona

\footnotetext{
${ }^{7}$ DC: cocuyo m. 1 Nombre de varios tipos de escarabajo volador, de hasta $3 \mathrm{~cm}$ de longitud, de color café claro y con un par de manchas que emiten luz en el tórax o el abdomen. [...]

${ }^{8}$ En el DC carro es "automóvil destinado al transporte de personas". El lema coche no figura en este diccionario.

En DLE: carro es 1. m. Carruaje de dos ruedas, con lanza o varas para enganchar el tiro, y cuya armazón consiste en un bastidor con listones o cuerdas para sostener la carga, y varales o tablas en los costados, y a veces en los frentes, para sujetarla. 2. m. Vehículo o armazón con ruedas que se emplea para transportar objetos diversos, como el cesto de la compra, libros, comida, equipaje, etc. ...] 9. m. Am. coche (automóvil).
} 
que padece los efectos del consumo de bebidas alcohólicas. 2. Referido a una persona que está triste. En el ejemplo LRP 129 es la acepción 1, además, el adjetivo está en diminutivo lo que provoca matices irónicos.

- ¿Cómo amanecieron, paisanos, muy enguayabaditos, o qué? - saludó al llegar.

"Enguayabados" es en Colombia, "crudos" en México, en Guatemala "con goma" y en España "con resaca" (LRP 129)

»Kako se počutite, rojaki, sinočnji, ali kako?«je pozdravil ob prihodu.

»Sinočnji« je v Kolumbiji »zmačkani«, v Mehiki in Gvatemali »zdelani« in v Španiji »skrokani«. (VU 107)

Siempre cuando el narrador/autor usa palabras diferentes en español peninsular y en el colombiano o americano, el traductor busca una salida para la traducción más o menos adecuada. En LRP 125 hay un juego de palabras que el traductor resuelve con los verbos eslovenos kavsati y kljuvati; ambos significan picotear, pero el primero también significa vulgarmente pichar, coger. La alusión a béisbol desaparece de la traducción eslovena.

- ¿ ¿Pichar"9 no quiere decir darle a una bola con un palo de béisbol?

- No, eso es "pichear" con "e". Para mí que de lo que el viejo estaba hablando era del acto del coito: el ayuntamiento, el apareamiento, la cópula. (LRP 125)

»Kavsanje pomeni kljuvanje ptic?«

»Ne, ne gre za to. Po mojem je imel starec v mislih spolni akt: združitev, parjenje, nečistovanje.« (VU 104)

En LRP 154 se destaca la palabra ordenador que se usa en España y computadora en Colombia (y en América en general). De acuerdo con la traducción eslovena el término computadora (kompjuter) se usaría en España, lo que no corresponde al original.

[...] ¿Me aconseja pegarme un tiro en la cabeza?

- En la cabeza no: en el corazón, preservando la computadora.

- O sea el ordenador, como decimos en España. En América hablan muy raro, mueven muy raro los labios. (LRP 154)

\footnotetext{
${ }^{9}$ En el DC: pichar v. 1 Caribe. En el béisbol y en deportes similares, lanzar el pícher la bola a su receptor evitando que el bateador del equipo contrario la golpee. 2 vulg. Tener relaciones sexuales.
} 
Mi svetujete, naj si poženem kroglo v glavo? »Ne v glavo: v srce, da se ohrani računalnik.» Oziroma kompjuter, kot rečemo v Španiji. V Ameriki govorijo zelo čudno, zelo čudno premikajo ustnice. (VU 129)

En el ejemplo que sigue, el traductor optó por no traducir una parte (colombianismo).

- ¡Qué hijueputas tan lambiscones! Lamiéndoles el culo a los muertos como si siguieran vivos. "Vaca vieja no olvida el portillo" decía la abuela. Lambiscones, que es mexicanismo, significa "lambones", que es colombianismo: aduladores, rastreros, de esos que sobran en el gran velorio de esta vida. (LRP 112-113)

»Kakšni prekleti laskači! Mrtvim ližejo rit , kot da bi bili še živi.« »Stara navada, železna srajca, « je rekla stara mama.

Laskači je mehiški izraz, ki je na pretek pomeni »priliznjenci«, se pravi podleži, hinavci, kakršnih je na pretek sredi tega velikega bedenja ob rakvi v tem življenju. (VU 93-94)

En esloveno existe la palabra kajman que corresponde exactamente a caimán (definido por el DLE como: "m. Reptil del orden de los emidosaurios, propio de los ríos de América, muy parecido al cocodrilo, pero algo más pequeño, con el hocico obtuso y las membranas de los pies muy poco extensas"), que el traductor tradujo como aligator, término menos usado, también en esloveno, para estos reptiles.

- Oiga señor, ¿y de veras el Magdalena tenía caimanes?

- Sí, los exterminaron. A todos los mataron para hacer con sus pieles zapatos de puta y cinturones de maricas. Colombia la vandálica los acabó. (LRP 125)

»Poslušajte, gospod, so bili v Magdaleni res aligatorji?« »Da, iztrebili so jih. Vse so pobili, da so iz njihove kože naredili čevlje za kurbe in pasove za pedre.Vandalska Kolumbija jih je pokončala.« (VU 103)

\section{Conclusiones}

Al comparar diferentes fenómenos lingüísticos y culturales del texto original con su traducción eslovena destaca el esfuerzo del traductor por trasladarlos a la lengua meta, sobre todo porque se trata de expresiones y usos típicos de una zona dada, en este caso el español de 
Colombia. La Rambla paralela de Fernando Vallejo es una novela compleja en la que abundan paralelismos temporales y espaciales, juegos de voces narrativas, diferentes estilos y registros tanto coloquiales como narrativos y descriptivos en una lengua rica con muchos elementos de la variante colombiana (y dentro de ella, antioqueña), con un sinfín de referencias socio-históricas, culturales y lingüísticas. De los ejemplos seleccionados se desprende que la labor traductora no ha sido fácil, no obstante en muchos casos el traductor supo llegar a resultados excelentes. El objetivo del artículo ha sido, pues, llamar la atención sobre algunos problemas de la traducción de La Rambla paralela al esloveno y comparar las dos versiones. Como ya se ha explicitado, la novela es rica en referencias socio-culturales e históricas y, desde el punto de vista lingüístico, en americanismos y colombianismos. La novela se caracteriza por un lenguaje cuidado y brillante con elementos de ironía, sarcasmo y diferentes registros de la lengua.

\section{BIBLIOGRAFÍA}

Alvar, Manuel (Dir.). Manual de dialectología hispánica. El Español de América. Madrid: Ariel, 1996. Impreso.

Corpas Pastor, Gloria. Manual de Fraseología Española. Madrid: Gredos, 1996. Impreso.

Espejo, Maria Bernarda. "Español de Colombia". Portal de lenguas de Colombia. Bogotá: Instituto Caro y Cuervo.

https://lenguasdecolombia.caroycuervo.gov.co/contenido/

Espanol-de-Colombia/introduccion\& Web. 01 Oct. 2019.

Flórez, Luis. "El español hablado en Colombia y su Atlas Lingüístico". Thesaurus XVIII, No. 2 (1963): 268-355. Impreso.

Haensch, Günter \& Reinhold Werner. Nuevo diccionario de americanismos. Nuevo diccionario de colombianismos. Santafé de Bogotá: Instituto Caro y Cuervo, 1993. Impreso.

Instituto Caro y Cuervo. Diccionario de colombianismos. Bogotá: ICC, 2018. Impreso.

Markič, Jasmina. "Traduciendo a Sergio Ramírez: reflexiones sobre la traducción de Margarita está linda la mar». Bohdan Ulašin (Ed.). ¿Quo vadis, romanística?. Bratislava: Univerzita Komenského v Bratislave, 2014: 141-152. Impreso.

Markič, Jasmina. "Voseo, tuteo in ustedeo v kolumbijski različici španščine". Jasmina Markič \& Barbara Pihler Ciglič (Eds.). Latinska Amerika: družbeno-zgodovinski, literarni in jezikovni vidiki. Ars \& humanitas 
11, 2. Ljubljana: Znanstvena založba Filozofske fakultete, 2017: 56-72. Impreso.

Montes Giraldo, José Joaquín. "Sobre el voseo en Colombia”, Thesaurus XXII/1 (1967): 21-44. Impreso.

Montes Giraldo, José Joaquín. Estudios sobre el español de Colombia, Bogotá: Instituto Caro y Cuervo, 1985. Impreso.

Musitano, Julia. "Detrás de una máscara fantasmagórica. Una lectura de La rambla paralela de Fernando Vallejo", Orbis Tertius, 17, No. 18, 2012. http://www.orbistertius.unlp.edu.ar Web. 20 Sep. 2019. Real Academia Española. Diccionario de la lengua española, 23. [versión 23.2 en línea]. https://dle.rae.es Web. 31 Ago. 2019. Slovar slovenskega knjižnega jezika (SSKJ), druga, dopolnjena in deloma prenovljena izdaja. Ljubljana: Inštitut za slovenski jezik Frana Ramovša ZRC SAZU. www.fran.si Web 10 Sep. 2019. Vallejo, Fernando. La Rambla paralela. Madrid: Alfaguara, 2002. Impreso. Vallejo, Fernando. Vzporedna ulica. Ljubljana: Modrijan, 2018. Traducción de Ferdinand Miklavc. Natisnjeno.

\section{TRANSLATING FERNANDO VALLEJO: LA RAMBLA PARALELA AND VZPOREDNA ULICA}

\section{Summary}

La Rambla paralela by Fernando Vallejo (Medellín, Colombia, 1942), published in 2002, is a novel of self-fiction with a specific treatment of the narrating voices that oscillate permanently between the first and the third person. An elderly Colombian writer is invited to speak at the Barcelona book fair in which the invited country is Colombia. The writer wanders around Barcelona and under the influence of alcohol and insomnia he immerses himself in his memories of the past. The times of the present, past and future merge as well as the parallel spaces through which the protagonist moves (Barcelona, Medellín, Mexico...).

This article analyzes some aspects of the translation, mostly lexical but also morphosyntactic, of the novel La Rambla paralela and its Slovenian version Vzporedna ulica (2018) translated by Ferdinand Miklavc, without neglecting the socio-cultural and historical framework that is reflected in the novel. Dialogues and speech of the colloquial and local sphere abound. The paper examines and comments on the translation compared to the original, especially with reference to colombianisms and the specific terms and phrases of the region that present one of the greatest obstacles for the translator.

Key words: Fernando Vallejo, translation, colombianisms, Antioquia, parallelisms. 